\title{
Review
}

\section{In Situ Localization of Gene-Specific Transcription Regulatory Factors by Southwestern Histochemistry}

\author{
Takehiko Koji \\ Department of Histology and Cell Biology, Nagasaki University School of Medicine, Sakamoto, Nagasaki 852-8523
}

Received January 21, 1999; accepted January 22, 1999

\begin{abstract}
To understand better the regulation of gene expression, an analysis of the expression of trans-acting transcription regulatory factors in individual cells is essential. Although cellular analysis of specific mRNA expression is successfully performed by in situ hybridization, the results are not enough to tell whether an elevated level of certain mRNA is due to an increased rate of transcription of the gene or due to a decreased rate of degradation of the mRNA. Recently, we have developed a new method, Southwestern histochemistry, which allows us to localize transcription regulatory factors in situ. In principle, double-stranded (ds) DNA harboring specific response element base sequences is synthesized and labeled with a hapten such as thymine-thymine (T-T) dimer

and digoxigenin (Dig). After the reaction of frozen tissue sections with the probe ds DNA, the signal is detected enzyme-immunohistochemically by horseradish peroxidase (HRP)-labeled anti-T-T dimer or anti-Dig, respectively. As a model system, we localized estrogen receptor (ER) in mouse uterine tissue sections by immunohistochemistry with 1D5 monoclonal antibody and Southwestern histochemistry using T-T dimerized estrogen responsive element (ERE) ds DNA of vitellogenin. Consequently, very similar localization of ER was obtained by both methods. This result, together with other examples, further indicates the usefulness of Southwestern histochemistry as a method to localize specific transcription regulatory factors in situ.
\end{abstract}

Key words: Southwestern histochemistry, Transcription factors, Nonradioactive, Doublestranded DNA probe, Immunohistochemistry

I. Scientific Merits of Analysis of Cellular Distribution of Gene-Specific Transcription Regulatory Factors

For these decades, in situ hybridization, the method to localize specific mRNA and DNA sequences in cell or tissue preparations, has been actively explored and now widely accepted as an essential tool especially in the fields such as cell biology, molecular pathology and developmental biology. As in the case of northern blot analysis of mRNA expression, however, it is apparent that the information on the expression of mRNA by in situ hybridi-

Correspondence to: Prof. Takehiko Koji, Department of Histology and Cell Biology, Nagasaki University School of Medicine, 1-12-4, Sakamoto, Nagasaki 852-8523, Japan. zation in itself represents only a steady-state level of gene expression [7]. Consequently, such information is usually not enough to tell whether an elevated level of certain mRNA is due to an increased rate of transcription of the gene or due to a decreased rate of degradation of the mRNA. Thus, for a more precise understanding of the regulation of gene expression, one would require an analysis of the expression of gene-specific transcription regulatory factors at an individual cell level. Those proteins, such as c-Myc [6], c-Jun [2], CREB [14] and various steroid hormone receptors [1], bind to specific consensus sequences in a part of genomic DNA known as a responsive element, which is commonly located in the promoter region of a certain gene, and regulate transcriptional activity of the genes harboring the element. To date, however, in most of the transcription regulatory factors 
reported so far, there is only a little information on their cellular distribution because of the limited availability of specific antibodies which may allow us to localize those proteins. Considering that the expression level of those proteins is generally too low to be purified at a sufficient amount to raise antibodies against them, we needed to explore a new methodology.

\section{Transcription Regulatory Factors}

As shown in Fig. 1, transcription regulatory factors, which regulate transcriptional activity of a gene, are divided into two categories; one consists of general transcription factors which bind to TATA box or other consensus sequences as a transcription machinery complex and transcribe the DNA sequences of genes directly, and the other consists of gene specific transcription regulatory factors which bind to a specific responsive element in the promoter region of genes and regulate the transcription activity of the genes harboring the responsive element. What we are interested in now is the latter factors. Those proteins can be firstly identified as a factor bound to a specific DNA element which is involved in the regulation of gene transcription, so the base sequence of the binding site may be determined at the same time by DNase I foot-printing. Therefore, in many cases we can know the specific base sequences of a responsive element to be recognized and bound by the transcription regulatory factor, even though no further information on the protein is available.

\section{Development of Southwestern Histochemis- try}

During our efforts to optimize the protocol for nonradioactive in situ hybridization using rat pituitary sections in 1985, we encountered a strange phenomenon. In the experiment, we hybridized the pituitary sections with dinitrophenyl (DNP)-labeled proopiomelanocortin (POMC) cDNA and the expression of POMC mRNA was analyzed enzyme-immunohistochemically with anti-DNP antibody [8]. As shown in Fig. 2, the specific staining of POMC mRNA was found in the intermediate pituitary cells as well as some cells of the anterior pituitary at a relatively high concentration of proteinase K. Surprisingly, a bacterial plasmid pBR 322 DNA, which was used as a negative control probe, gave rise to some staining in a very similar distribution pattern to that of POMC mRNA, but only at lower concentrations of proteinase $\mathrm{K}$. Later, we realized that the distribution of the "specific" proteasesensitive staining with pBR 322 DNA was quite similar to that of glucocorticoid receptor (GR). Therefore, it was really exciting to find the report in which pBR 322 DNA contains glucocorticoid responsive element (GRE) consensus sequences at five sites and actually can bind to GR on southwestern blots [16]. Our previous finding now can be interpreted in a way that pBR 322 DNA may bind to GR in the tissue section. This interpretation is also consistent with the fact that GR consists of three autonomous domains; trans-activation domain, DNA-binding domain and hormone-binding domain, and regulates gene expression through its binding to specific DNA sequences, called "GRE", located in the vicinity of the regulated gene $[1,3]$.

Based upon the unexpected findings, we attempted to localize GR by utilizing the specific interaction between GR and GRE; frozen sections of rat liver were reacted with T-T dimerized pBR 322 DNA and the T-T dimers were detected enzyme-immunohistochemically by the successive use of rabbit anti-(T-T dimer) antibody and HRP-anti(rabbit IgG). Consequently, specific staining was confirmed in the nuclei, nuclear membranes as well as

\section{Transcriptional Control of Gene Expression}
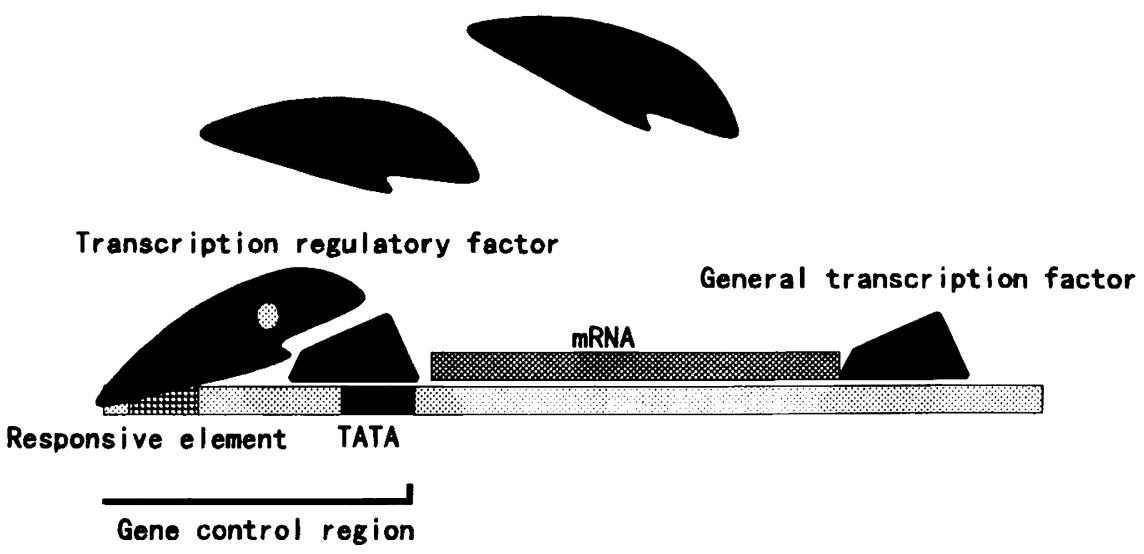

Fig. 1. Schematic presentation of the regulation of gene transcription. There are two categories in transcription regulatory proteins. One is a group of proteins forming transcriptional machinery and is involved in the transcription of genes directly by binding to TATA box or other consensus sequences as general transcription regulatory factors. Another group consists of gene specific transcription regulatory factors, which bind to the specific responsive element consensus sequence in the gene regulatory region of the target genes and are activated to control the activity of transcriptional machinery. 


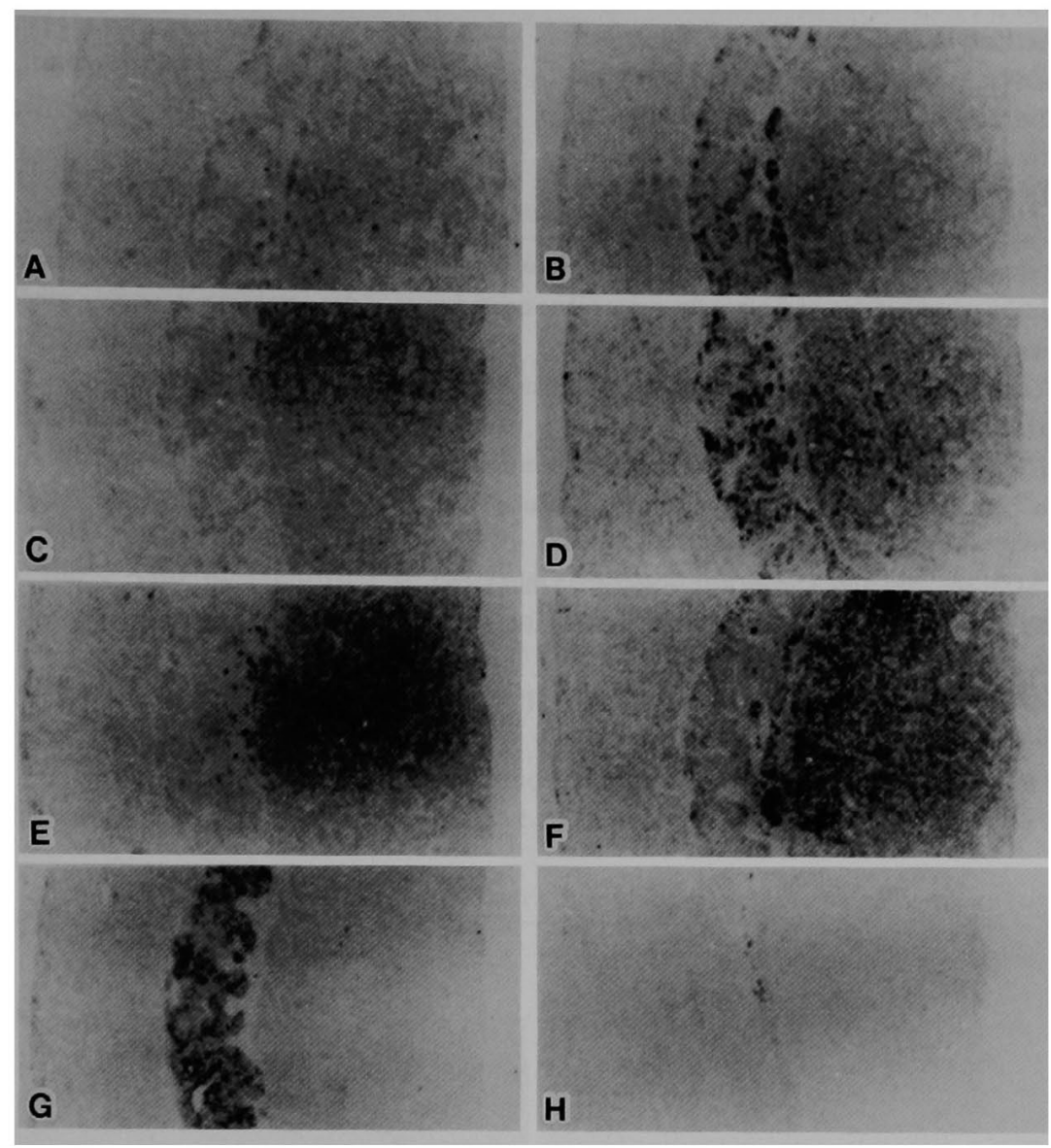

Fig. 2. In situ localization of POMC mRNA in the paraffin sections of rat pituitary gland [8]. As described in the text, the paraffin sections of rat pituitary gland were hybridized in situ with DNP-labeled POMC cDNA (A, C, E, G) and DNP-labeled pBR 322 DNA (B, D, F, H) and the signal was detected enzyme-immunohistochemically [8]. In this experiment, the effects of increasing concentrations of proteinase $\mathrm{K}\left(37^{\circ} \mathrm{C}\right.$, $15 \mathrm{~min}$ ) on the signal detection was investigated, since the optimization of proteinase digestion conditions is the most important factor to achieve the best performance of nonradioactive in situ hybridization [7, 8]. (A, B);0 $0 \mathrm{~g} / \mathrm{ml},(\mathbf{C}, \mathbf{D}) ; 1 \mu \mathrm{g} / \mathrm{ml},(\mathbf{E}, \mathbf{F}) ; 10 \mu \mathrm{g} / \mathrm{ml},(\mathbf{G}, \mathbf{H}) ; 100 \mu \mathrm{g} / \mathrm{ml}$ A, anterior pituitary; I, intermediate pituitary; P, posterior pituitary. At $100 \mu \mathrm{g} / \mathrm{ml}$ of proteinase $\mathrm{K}$, the specific signal for POMC mRNA was observed in the intermediate pituitary cells and some cells of the anterior pituitary. However, a clear staining with a similar distribution pattern to that of POMC mRNA was obtained in the sections reacted with pBR 322 DNA at lower concentrations of proteinase $\mathrm{K}$.

\section{Southwestern Histochemistry}

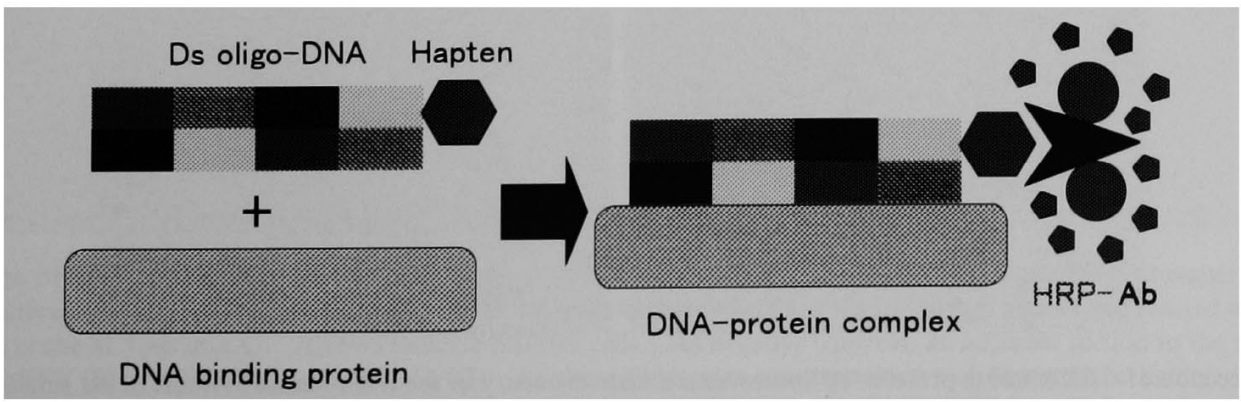

Fig. 3. Schematic presentation of Southwestern histochemistry. (1) The $(+)$ and $(-)$ strands of specific DNA consensus sequence in target response element are synthesized and annealed after synthesis. The 3' ends of both strands are labeled with a haptenic compound such as T-T dimer or Dig. (2) The double-stranded oligo-DNA with a hapten is reacted with tissue sections. (3) Finally, HRP-labeled anti-hapten antibody is reacted with the sections and the sites of HRP are visualized with 3,3'-diaminobenzidine-4HCl (DAB) and hydrogen peroxide in the presence of nickel and cobalt ions [11]. 
cytoplasm of hepatocytes $[9,10]$. The success encouraged us to combine the method with the use of synthetic double-stranded oligo-DNA, as described schematically in Fig. 3. In principle, the use of haptenized oligo-DNA is more specific and more convenient than segments of DNA [10] or radiolabeled oligo-DNA [5]. We originally named this newly developed method "Oligo-histochemistry" [9, 10 ], but later renamed it "Southwestern histochemistry"

Chart 1. Procedures for Southwestern histochemistry using fresh frozen sections.

1. Freeze fresh tissue samples embedded in OCT compound (Miles Inc.) as quickly as possible using an ethanol/dry ice bath.

2. Cut sections at a thickness of 5-6 $\mu \mathrm{m}$ and place them on silane-coated glass slides according to routine procedure (unless otherwise specified, all steps are performed at room temperature).

3. Fix with $4 \%$ paraformaldehyde in PBS (pH 7.4) at $4^{\circ} \mathrm{C}$ for $10 \mathrm{~min}$.

4. Wash 3 times with PBS for 5 min each.

5. Immerse in $50 \mathrm{mM}$ Tris $/ \mathrm{HCl}$ buffer (pH 7.4) containing $5 \%$ non-fat dry milk, $50 \mathrm{mM} \mathrm{NaCl}$ and $1 \mathrm{mM}$ EDTA (TMSE) for $1 \mathrm{hr}$.

6. Put $20-30 \mu \mathrm{l}$ of the TMSE solution including T-T dimerized probe DNA at $1-5 \mu \mathrm{g} / \mathrm{ml}$ on each slide and keep it in a moist chamber overnight.

7. Wash twice with TMSE solution and 3 times with PBS for 15 min each.

8. Put $30-40 \mu \mathrm{l}$ of PBS containing $5 \%$ BSA, $500 \mu \mathrm{g} / \mathrm{ml}$ normal mouse IgG, and $100 \mu \mathrm{g} / \mathrm{ml}$ salmon testis DNA on each slide and let it stand for $30 \mathrm{~min}-1 \mathrm{hr}$ in a moist chamber.

9. React with 30-40 $\mu$ l of HRP-labeled mouse monoclonal anti-(T-T dimer) antibody (Kyowa Medex, $1: 80$ ) dissolved in PBS containing $5 \% \mathrm{BSA}$ and $100 \mu \mathrm{g} / \mathrm{ml}$ salmon testis DNA for $30 \mathrm{~min}-3 \mathrm{hr}$.

10. Wash 4 times with $0.075 \%$ Brij35 in PBS for 15 min each and once with PBS alone for 5 min.

11. Visualize the HRP sites in a chromogen solution containing $0.5 \mathrm{mg} / \mathrm{ml} \mathrm{DAB}, 0.01 \% \mathrm{H}_{2} \mathrm{O}_{2}, 0.02 \% \mathrm{NiSO}_{4}\left(\mathrm{NH}_{4}\right)_{2} \mathrm{SO}_{4}$ and $0.025 \%$ $\mathrm{CoCl}_{2}$.

12. Dehydrate with serial up-graded ethanol solutions, clear with xylene and mount.

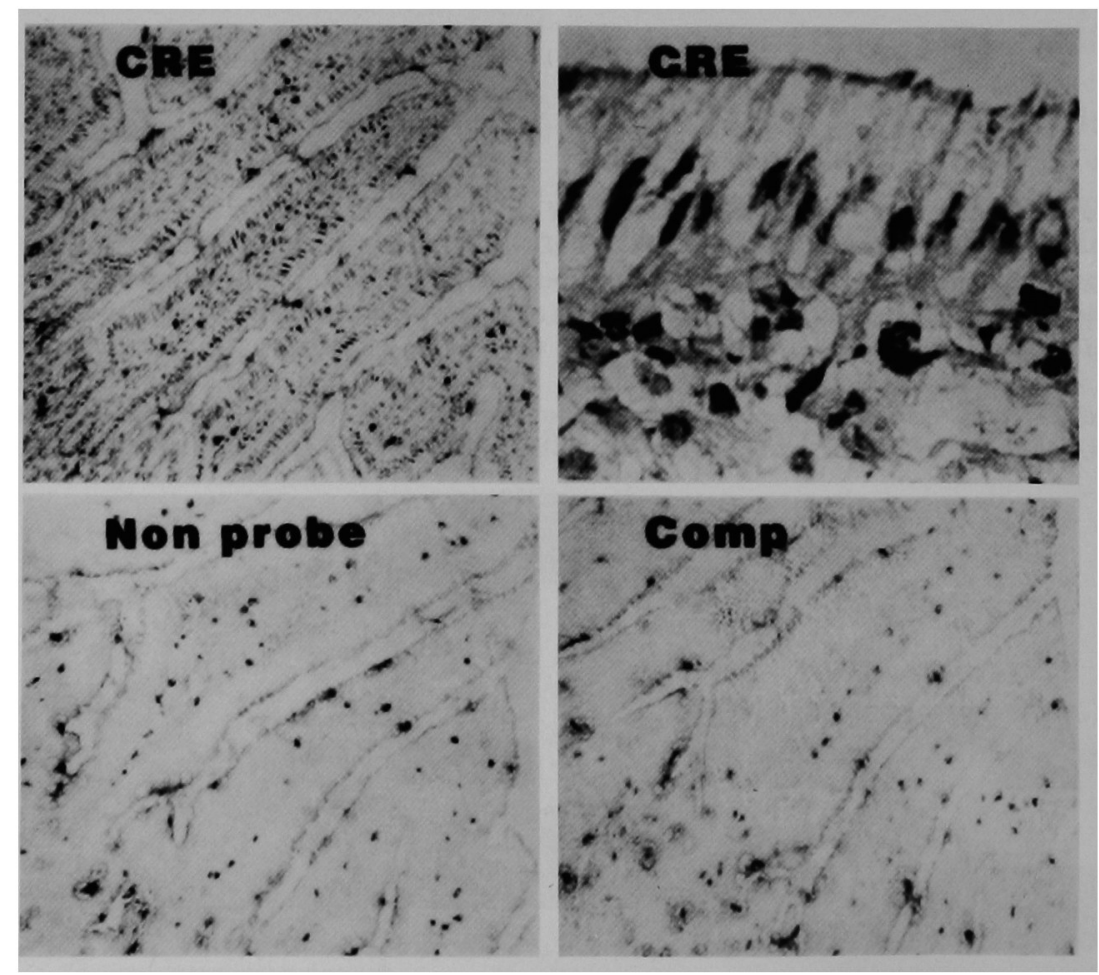

Fig. 4. In situ detection of CRE-binding proteins by Southwestern histochemistry in the fresh frozen sections of rat small intestine [11]. The fresh frozen sections of rat small intestine were fixed with 4\% paraformaldehyde in PBS and reacted with T-T dimerized CRE double-stranded oligo-DNA probe $(\mathrm{CRE})$; the left panel (magnification; $\times 125$ ) is a low-power view and the right panel (magnification; $\times 800$ ) is a high-power view. (Non probe); a section was processed omitting only the probe DNA. Magnification; $\times 125$. (Comp); a section was reacted with the CRE probe in the presence of an excess amount of non-labeled CRE DNA (102-fold). Magnification; $\times 125$. In the CRE panels, the strong staining of epithelial nuclei of small intestine was found, whereas in a Non probe section and a Comp section no signal was detected, except for the staining for endogenous peroxidase activity. 
[11] owing to the apparent similarity in principle to that of southwestern analysis [15]. Our standard protocol was shown in Chart 1.

\section{Application}

1) Localization of cyclic adenosine $3^{\prime}, 5^{\prime}$-monophosphate (CAMP) responsive element (CRE) binding proteins by Southwestern histochemistry. As a model system to demonstrate the usefulness of haptenized oligoDNA for the localization of specific transcription factors at the level of individual cells, CRE binding protein was localized in the frozen sections of rat brain and rat small intestine (Fig. 4) $[9,11]$. We synthesized the CRE consensus base sequence ( $5^{\prime}$-TGACGTCA-3') together with three TTA repeats at the 5 -end and allowed it to be annealed, as given below:

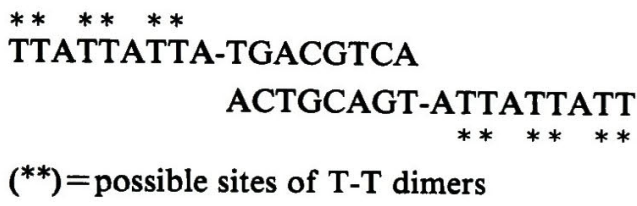

$\left({ }^{* *}\right)=$ possible sites of $\mathrm{T}-\mathrm{T}$ dimers

Before use, the double-stranded CRE oligo-DNA was T-T dimerized by UV irradiation. When the sections of those tissues, which were known to be responsive to cAMP, were reacted with the haptenized probe, the brain cell and intestinal epithelial nuclei were heavily stained and the staining intensities could be altered by physiological manipulation [11].

2) Localization of estrogen receptor (ER) $\alpha$ by Southwestern histochemistry. One more example, I would like to show here, is to demonstrate the cellular distribution of ER $\alpha$ in the frozen sections of mouse uterus. The uterine tissue is pertinent as a model case for analysis of $\operatorname{ER} \alpha$, since no expression of $\operatorname{ER} \beta$ was reported in uterus [13]. In Fig. 5, ER was detected by both Southwestern histochemistry and immunohistochemistry, and the results were compared. For Southwestern histochemistry of ER, we synthesized double-stranded oligo-DNAs containing complete palindromic estrogen responsive element (vERE: 5'-GATCCAGGTCACAGTGACCTGGATC-3') of chicken vitellogenin gene and a mutated estrogen responsive element (mERE: 5'-GATCCAGATCACAGTGATCTGGATC-3') with two-base mutation [4], together with

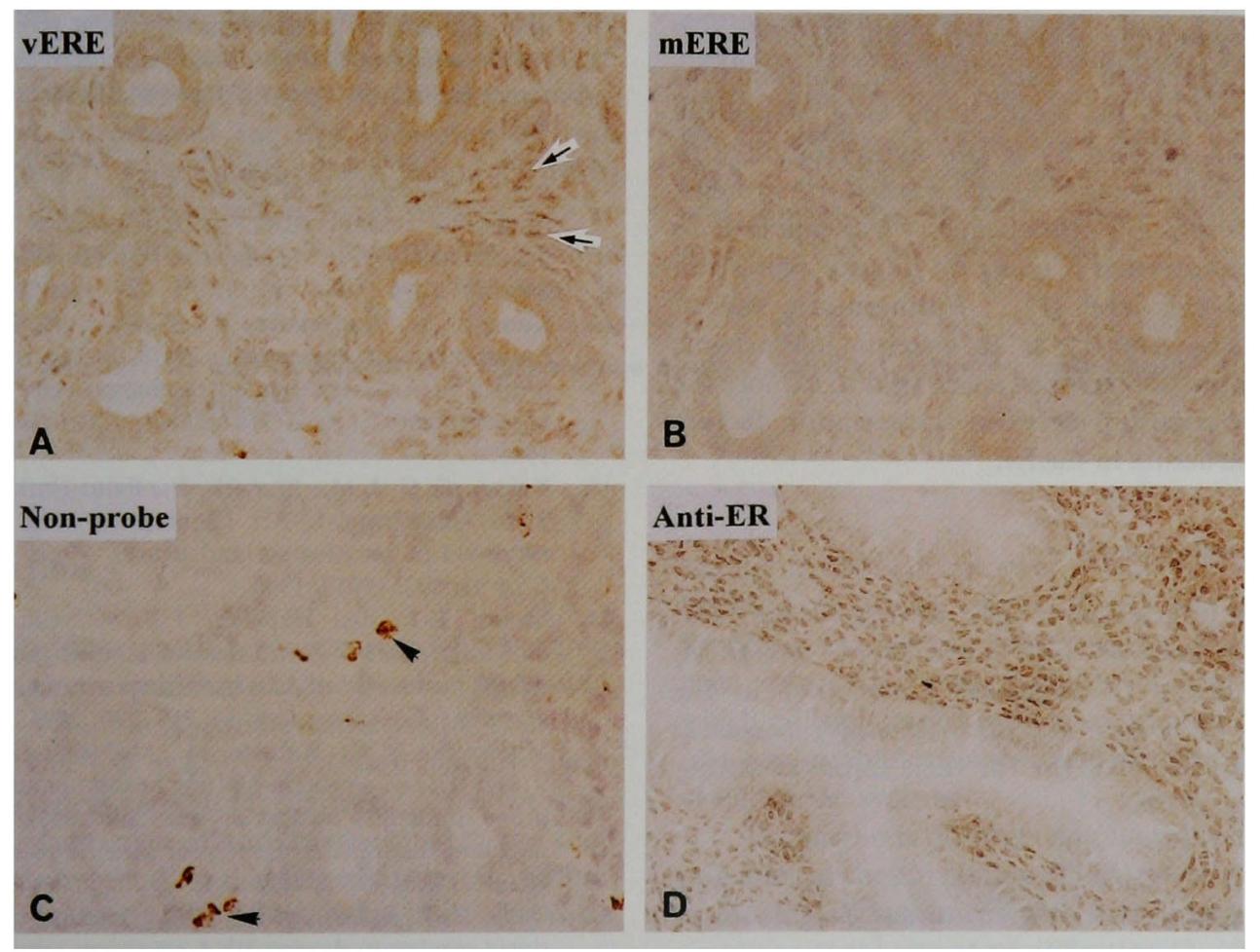

Fig. 5. Localization of ER $\alpha$ in frozen sections of mouse uterus by Southwestern histochemistry and immunohistochemistry. A fresh frozen section of mouse uterus (at the diestrus stage) was fixed with $4 \%$ paraformaldehyde in PBS for 10 min at $4^{\circ} \mathrm{C}$ and reacted with T-T dimerized vERE oligo-DNA probe at $5 \mu \mathrm{g} / \mathrm{ml}$ (A). Arrows indicate positive cells. As negative controls, an adjacent section to the section used in (A) was reacted with mERE (B) or without any probe DNA (C). All those slides were counterstained with hematoxylin lightly. (D) A fresh frozen section was fixed with $4 \%$ paraformaldehyde in PBS for 10 min at $4^{\circ} \mathrm{C}$, preincubated with $1 \% \mathrm{BSA} / \mathrm{PBS}$ for 30 min at room temperature (RT) and then reacted overnight with monoclonal anti-ER antibody (1D5, 1:100, DAKO) dissolved in 1\% BSA/PBS at RT. After appropriate washing with PBS containing $0.075 \%$ Brij35, HRP-labeled goat anti-mouse Ig (1:100, Chemicon) dissolved in 1\% BSA/PBS was reacted for $1 \mathrm{hr}$ at RT. Then the slides were washed with PBS containing $0.075 \%$ Brij35 and the sites of HRP were visualized with DAB and hydrogen peroxide in the presence of nickel and cobalt ions [7]. Arrow heads indicate the staining for endogenous peroxidase activity. Magnification; $\times 300$ (for A-C) and $\times 150$ (for D). 
three TTA repeats at the $3^{\prime}$-end. When the fresh frozen sections of mouse uterus at the stage of diestrus were fixed with 4\% paraformaldehyde in PBS and reacted with the vERE probe, the nuclei of stromal cells were stained (Fig. 5A). The staining pattern of ER by Southwestern histochemistry seemed to be well consistent with that of ER $\alpha$ detected by immunohistochemistry (Fig. 5D). In principle, ER $\beta$ [13] should react with the vERE probe in Southwestern histochemistry. Therefore, the combination of Southwestern histochemistry for $\operatorname{ER} \alpha$ and/or $\beta$ and immunohistochemistry for $\mathrm{ER} \alpha$ provides a simple solution to discriminate the expression of both ERs in individual cells. In addition, no nuclear staining was found when the adjacent sections of mouse uterus were reacted with mERE or without any probe (Fig. 5B, C).

\section{In the Future}

Although the list of transcription factors and their responsive elements has been rapidly growing, appropriate antibodies for immunohistochemistry are not often available for most of these newly identified proteins. Therefore, Southwestern histochemistry should be useful for the localization of those factors at an individual cell level and for a better understanding of transcriptional regulation of specific mRNA expression. Especially, the combination of the information on the steady state level of specific mRNA expression assessed by in situ hybridization with the states of specific transcriptional regulatory proteins analyzed by Southwestern histochemistry will enable us to depict more precisely what is going on in gene expression at an individual cell level [12]. Furthermore, use of Southwestern histochemistry at an electron microscopic level will make it possible to open a new field to explore the topographical relationship between transcription factors and chromatin structure in nuclei.

\section{Acknowledgments}

The author is grateful to Dr. Rui-An Wang, Mr. Tatsuki Mizuochi and Mr. Eiji Muroi (T. M. and E. M. are medical students of Nagasaki University) in the Department of Histology and Cell Biology, Nagasaki University School of Medicine for their initial contribution on the study of ER $\alpha$.

\section{References}

1. Beato, M.: Gene regulation by steroid hormones. Cell 56; 335-344, 1993.
2. Curran, T. and Franza, R. B.: Fos and Jun: The AP-1 connection. Cell 55; 395-397, 1988.

3. Evans, R.M.: The steroid and thyroid hormone receptor. Science 240; 889-895, 1988.

4. Fritsch, M., Welch, R. D., Murdock, F. E., Anderson, I. and Gorski, J.: DNA allosterically modulates the steroid binding domain of the estrogen receptor. J. Biol. Chem. 267; 1823$1828,1992$.

5. Kato, T., Kato, T., Ezaki, T. and Inoue, K.: In situ binding for detection of proteins that bind to regulatory elements. Biochem. Biophys. Res. Commun. 195; 963-968, 1993.

6. Kerkhoff, E., Bister, K. and Klempnauer, K. -H.: Sequencespecific DNA binding by Myc proteins. Proc. Natl. Acad. Sci. USA 88; 4323-4327, 1991.

7. Koji, T. and Nakane, P. K.: Recent advances in molecular histochemical techniques: In situ hybridization and Southwestern histochemistry. J. Electron Microsc. 45; 119$127,1996$.

8. Koji, T., Moriuchi, T. and Nakane, P. K.: Improved tissue preparation for in situ localization of specific mRNA using non-radioactive DNA probes: Effects of protease digestion and probe size on signal detection in frozen and paraffin sections of rat pituitary glands. Acta Histochem. Cytochem. 21; 187-200, 1988.

9. Koji, T., Yamada, S., Izumi, S. and Nakane, P. K.: Oligohistochemistry. A new approach to localize DNA-binding proteins. J. Histochem. Cytochem. 38; 1052, 1990.

10. Koji, T., Yamada, S., Kayashima, K. and Nakane, P. K.: A new approach to localize glucocorticoid receptor using DNA probe containing glucocorticoid responsive element DNA consensus sequences. Acta Histochem. Cytochem. 25; 681-687, 1992.

11. Koji, T., Komuta, K., Nozawa, M., Yamada, S. and Nakane, P. K.: Localization of cyclic adenosine $3^{\prime}, 5^{\prime}$-monophosphateresponsive element (CRE)-binding proteins by southwestern histochemistry. J. Histochem. Cytochem. 42; 1399-1405, 1994.

12. Komuta, K., Kanematsu, T., Nakane, P. K. and Koji, T.: Localization of epidermal growth factor receptor enhancer protein in A431 epidermoid carcinoma cells by Southwestern histochemistry. Acta Histochem. Cytochem. 31; 267-273, 1998.

13. Kuiper, G. G. J. M., Enmark, E., Pelto-Huikko, M., Nilsson, S. and Gustafsson, J. -A.: Cloning of a novel estrogen receptor expressed in rat prostate and ovary. Proc. Natl. Acad. Sci. USA 93; 5925-5930, 1996.

14. Meyer, T. E. and Habener, J. F.: Cyclic adenosine 3',5'monophosphate response element binding protein (CREB) and related transcription-activating deoxyribonucleic acid-binding proteins. Endocrine Rev. 14; 269-290, 1993.

15. Miskimins, W. K., Roberts, M., McClelland, A. and Ruddle, F. H.: Use of a protein-blotting procedure and a specific DNA probe to identify nuclear proteins that recognize the promoter region of the transferrin receptor gene. Proc. Natl. Acad. Sci. USA 82; 6741-6744, 1985.

16. Tully, D. B. and Cidlowski, J. A.: pBR322 contains glucocorticoid regulatory element DNA consensus sequences. Biochem. Biophys. Res. Commun. 144; 1-10, 1987. 